Sonic Scope: New Approaches to Audiovisual Culture

\title{
Rubie: Community in Isolation
}

Josh Grey-Jung

Published on: Feb 15, 2021

License: Creative Commons Attribution 4.0 International License (CC-BY 4.0). 


\begin{abstract}
Rubie: Community in Isolation

Josh Grey-Jung, Goldsmiths, University of London

Rubie is a portrait film by Josh Grey-Jung that follows artist and musician Rubie Green as they prepare for their album release performance. After just two days of filming, a nationwide lockdown is employed to curb the spread of the Covid-19 virus. The film subsequently becomes an exploration of Rubie's identity, paralleling their experience of isolation under new lockdown measures with their experience of marginalisation as a trans non-binary person. These ideas are expanded upon in the accompanying paper, which draws on queer studies to challenge normative models of 'success' and 'failure,' and posits lockdown as a radical, 'queer' alternative to the 'normality' of day-to-day life in a heteronormative capitalist society.
\end{abstract}

\title{
Rubie (Documentary Film)
}

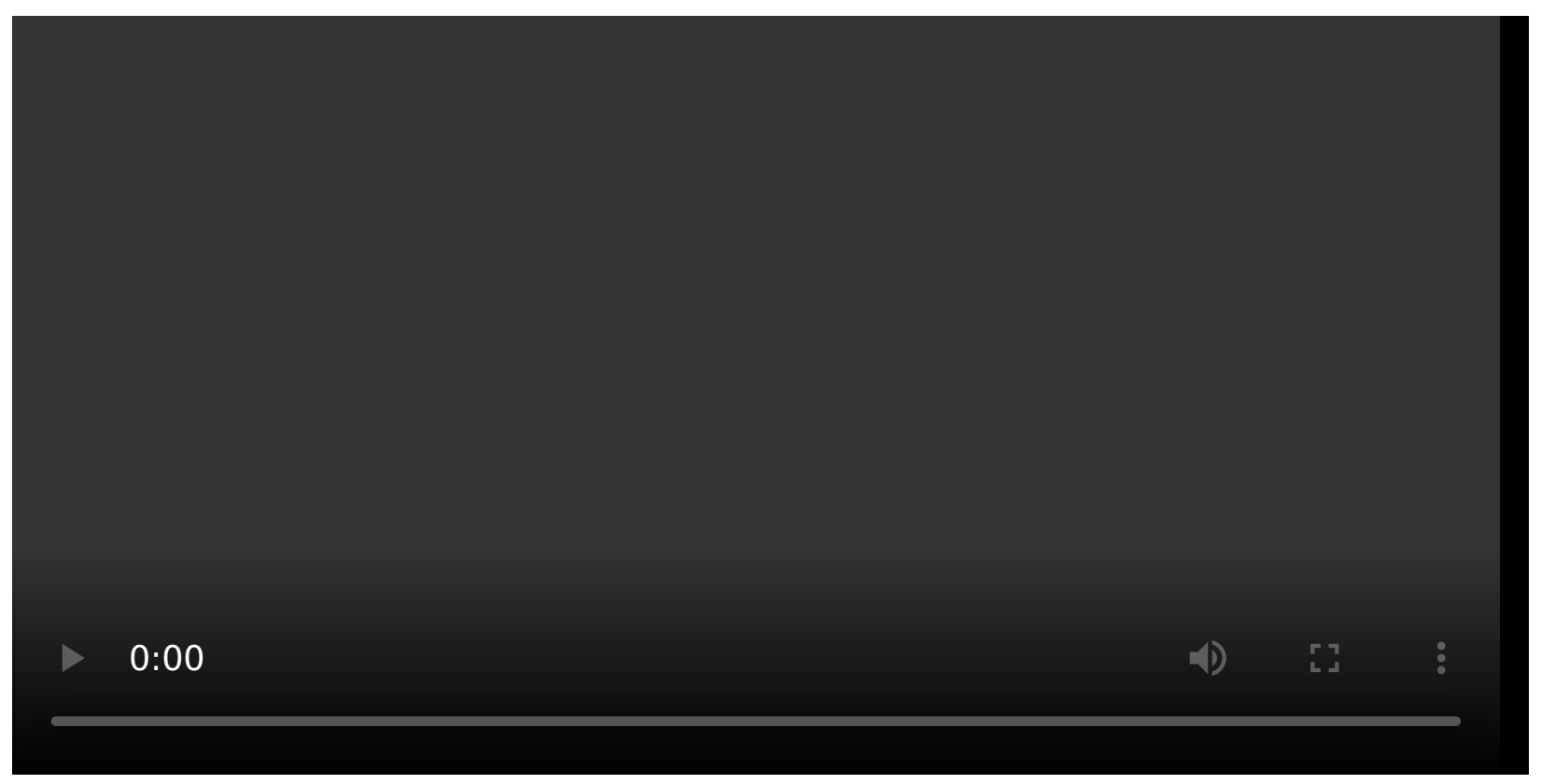

\section{Introduction}


To begin an ethnographic project with a goal, with an object of research and a set of presumptions, is already to stymie the process of discovery; it blocks one's ability to learn something new that exceeds the frameworks with which one enters. $\frac{1}{}$

For most of us, the weeks leading up to the first national lockdown in March 2020 were a confusing blur of mounting media coverage, conflicting government guidelines and polarised public opinion. The government's lack of clear strategy and delayed action only served to compound feelings of uncertainty, and the period of isolation that followed had a huge impact on people's lives. This affected housing, employment, access to food and healthcare, and in turn fuelled feelings of anxiety, loneliness, disorientation and fear. Yet, for some of us, the lockdown also provided a much needed moment of pause. A chance to recover, to resensitise and re-orientate ourselves in the here and now. It was in these circumstances that the film Rubie was created.

Rubie began as an attempt to document the musical journey of singer-songwriter Rubie Green as they prepared for their album release party. Following the national coronavirus lockdown on 23rd March 2020, numerous obstacles arose, complicating the production and post-production process and forcing me to re-imagine, re-shoot and re-edit the material. With only two days of filming in the can, the project subsequently evolved into an exploration of Rubie's identity, utilising mobile phone and Zoom recordings to explore their experience of isolation under lockdown alongside their experience of marginalisation as a transgender person. The film climaxes with an uplifting scene in which Rubie and the other members of the feminist $\mathrm{F}^{*}$ Choir are seen singing together in a group Zoom call. This ending offers viewers the redemptive message that supportive communities can provide salvation in an often divided and exclusionary world.

When situating myself within this global experience of Covid-19, I became increasingly aware of the privileged position I found myself in: my access to food, water, shelter, healthcare and government funding schemes, as well as the advantage of being child-free with no immediate family relying on me for financial support. Without wishing to trivialise or diminish peoples' experiences during the pandemic, it remains important to note the role that Covid-19 had in shaping the film, impacting both my journey as a filmmaker and Rubie's journey as a musician. While I realise the devastating impact that Covid-19 has had, and continues to have, throughout the world, the pandemic nevertheless generated a multitude of new creative opportunities for both Rubie and myself, forcing me to reexamine conventional notions of failure and success, and embrace a more experimental approach to the subject matter, drawing on queer theory to reinforce the political messages engendered by my subsequent creative decisions. Such ethical concerns also extended to the process of making this film, during which I remained cognizant of my own identity as a cisgender filmmaker portraying a transgender subject, as will be further discussed below. 


\section{(Dis)Orientation and The Digital}

A space to not know, and to not understand. $\underline{2}$

In her book Queer Phenomenology: Orientations, Objects, Others, Sara Ahmed contests that "moments of disorientation," such as those that became commonplace amid the Covid landscape, "are vital. They are bodily experiences that throw the world up, or throw the body from its ground." 3 She goes on to state that it is "what we do with such moments of disorientation [and] ... what such moments can do ... [that] offer us the hope of new directions." 1 f found these ideas embodied in Rubie's lived experience as a gender non-conforming person negotiating the pressures of a dominant, heteronormative culture. This is also exemplified in their role as an experimental songstress writing deconstructed pop music through DIY approaches to recording and performance, and as an artist navigating the isolation of lockdown and seeking new ways of "connecting people" (00:10:19) through their creativity. In Rubie, I attempted to forefront these aspects of their identity whilst trying to create an evocative portrayal of the global pandemic's disorientating effect on creativity and community. This disorientation is made evident as Rubie confesses to their personal struggles with isolation, detailing how it has impacted their ability to write and perform music: "in terms of writing it's been qulite difficult ... so much of what's going on hasn't been ... internalised or intellectualised in me at all" (00:05:52).

In order to visually illustrate this sense of disorientation, I employed several filmmaking devices, most notably the recurring close-up shots of Rubie's face (see for example 00:03:34; 00:07:10). The pixelated, lo-fi quality of these images create a sense of visual discordance with the DSLR footage that makes up the majority of the film. These moments are used as a visual device to both 'disorient' the viewer within the film, but also to 'orientate' the viewer within the shared virtual space of Zoom meetings which became commonplace during lockdown. As many of us know from first hand experience, Zoom is both a space where we are reminded of our separation and isolation, as well as our potential for social connection.

In the context of the film, the digital realm provided by Zoom becomes a site of creative potential, "offering," as Holly Rogers notes, "interactivity in a time of absolute inactivity." $\underline{5}$ In her keynote speech Quarantined Listening: The Cyber Remediation of City Soundscapes During Lockdown at the CysMus YouTube and Music Conference in 2020, Rogers addresses the "mediation of sonic artifacts during the 2020 pandemic" and states that "as the world retreated indoors during Covid-19, cyber culture became a significant tool for creative expression and partnership." $\underline{6}$ Deprived of their ability to perform in public, or record with $\mathrm{F}^{*} \mathrm{Choir}$ in person, Rubie is forced to seek out online alternatives. However, whilst these technologies offer creative workarounds to the limitations imposed by 
lockdown, they are poor replacements for physical human interactions. As Rubie states, "I miss touching people ... I'm definitely naturally someone who's not very good at reaching out to people via text and stuff ... I'm more of a ... face-to-face ... kind of person ... I miss those sorts of connections a lot" (00:08:35). By exploring the tension between these two sides of the lockdown experience, I hoped to convey the adaptability of human nature, whilst raising uncomfortable questions about the rapid digitisation of culture and our complicity in it.

\section{The Queer Art of Failure}

Failing is something queers do and have always done exceptionally well.?

As outlined by Jacek Kornak in Queer as a Political Concept, the term 'queer' holds a multiplicity of meanings within contemporary sexual politics. Originating as a pejorative term for homosexuals, this label was reclaimed in the 1980 s as a "weapon to challenge and transform politics." 8 David Halperin, meanwhile, has asserted that "queer is by definition whatever is at odds with the normal, the legitimate, the dominant. There is nothing in particular to which it necessarily refers. It is an identity without an essence." 'Q 'Queer' then, demarcates not a positivity but a positionality vis-à-vis the normative. In The Queer Art of Failure, Jack Halberstam argues that "success in a heteronormative, capitalist society equates too easily to specific forms of reproductive maturity combined with wealth accumulation ... if the boom and bust years of the late twentieth century and the early twenty-first have taught us anything, we should at least have a healthy critique of static models of success and failure." Building on Ahmed's notions of disorientation, Halberstam goes on to clarify that "failing, losing, forgetting, unmaking, undoing, unbecoming, not knowing may in fact offer more creative, more cooperative, more surprising ways of being in the world." $\underline{10}$ When considering the numerous ways in which the global pandemic has exposed the weaknesses of capitalism, these ideas take on new urgency and may provide some alternative tools for orientating ourselves in these unprecedented times.

To explore Rubie's queerness is to explore the relationship between the dominant discourse of cisgender heteronormativity and the subjugated discourse of non-binary genders and sexualities. In the context of the film, the dominant discourse is the DSLR footage - its quality is better and it is more recognisable to the viewer as being of a professional standard - while the DIY aesthetic of the iPhone/Zoom footage forms a subjugated discourse, as it would ordinarily be deemed 'less than' and therefore perhaps excluded from the final cut of the film. By including this footage, I sought to avoid 
reproducing Rubie's experience of marginalisation as a person who is considered 'less than' because they are not cisgender. This marginalisation is explored further when Rubie addresses the subject of performativity (00:06:20). During this scene, Rubie notes that they are more likely to be a target of street harassment when they are "dressing down" than when they are "dressing really outlandishly." This suggests that there is a highly performative version of transfeminine identity which is more widely accepted, perhaps due to the visibility of drag in popular culture with television shows such as RuPaul's Drag Race (Nick Murray, 2009-present). This idea is also explored by Halberstam, who states that "shadow feminisms ... have long haunted the more acceptable forms of feminism that are oriented to positivity, reform, and accommodation rather than negativity, rejection, and transformation." 11 Other examples can be found in Duncan Tucker's Transamerica (2005) which "can be interpreted as a queering - or more precisely, a transgendering - of the standard road movie format." 12 In her article "The Audiovisual Construction of Transgender Identity in Transamerica," Susan Välimäki states that the medium itself can be an instrument for change and that "films are among the most powerful social technologies for creating, sustaining, shaping, and renegotiating conceptions of gender." 13 By including footage of Rubie "dressing down" both sartorially and in the style of visual shooting, I hoped to affirm rather than oppress the less culturally celebrated aspects of their presentation. In giving voice to alternative "ways of being in the world," I was attempting to counteract the dehumanisation that they experience as a result of prejudice and discrimination within our society. $\underline{14}$

It is also worth considering the inherently 'queer' experience of lockdown as a radical alternative to the 'normality' of day-to-day life. As touched upon earlier, this period of societal collapse has provided the nation with an opportunity to pause and reflect on the failures of our system. As Rubie states, "maybe it is neoliberal brainwashing on my part that I feel any sort of need to continue to make things, to continue to be productive when, like, the world is collapsing" (00:03:51). In the film, this intimate and honest reflection is abruptly punctuated by the oppressive sound of a pneumatic drill, recorded at the building site outside Rubie's studio. This editing decision was initially born out of accident; however, on further reflection I considered how the drilling sound came to symbolise the normative sociopolitical influences that deny Rubie the space for "a bit of despair and a bit of inaction," pressure Rubie to conform and demand Rubie to (re)produce and 'succeed.' As Halberstam reflects, "relieved of the obligation to keep smiling ... the negative thinker can use the experience of failure to confront the gross inequalities of everyday life." $\underline{15}$

Halberstam's ideas also seem to permeate the production and post-production of Rubie, a process that led me to 'undo' and 'unmake' the film that I initially set out to shoot. In doing so, I was forced to step into the 'unknown' and embrace a degree of uncertainty, which in turn led to more "creative ... cooperative ... and surprising" outcomes. $\underline{16}$ 


\section{Production, Post Production and Ethical Concerns}

I'm often a bit wary of being, sort of, labeled as a sort of queer artist or a trans artist. $\underline{17}$

I approached the production of Rubie with an awareness of my privilege as a white heterosexual man who identifies as male, and throughout the process remained wary of typecasting or reducing Rubie's experience to a predetermined narrative. $\underline{18}$ I attempted to engage with Rubie openly and inquisitively, and relied on the "precariousness of the present moment" to propel our interactions forward. $\underline{19}$ In order to achieve this, I applied both observational and participatory modes of documentation: observational in that I paid close attention "to the complex sensory experience of gestures, looks, colours, and textures as much as to propositional forms of language" that arose in my encounters with Rubie; and participatory in the sense that I actively engage with Rubie throughout the film in interviews and conversation, thereby giving the viewer the "sense that [they] are witness to a form of dialogue between filmmaker and subject that stresses situated engagement, negotiated interaction, and emotion-laden encounter." $\underline{20}$ I also allowed this observational sensibility to inform some of my editing decisions in the post-production process, where I chose to forefront "experiential and interpretive possibilities" over "explanatory and definitive statements." $\underline{21}$

Throughout the filming process I tried to maintain an acute awareness of my subject, my surroundings, and the impact that my own presence had on them. I wanted to remain sensitive to the nuances and idiosyncrasies of Rubie's character in the hope that this open attention would in turn

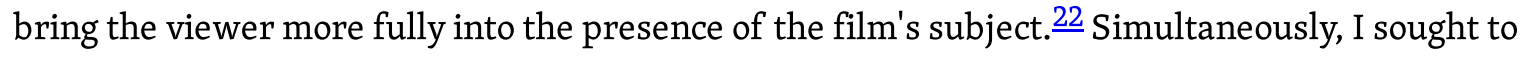
nurture a friendly and collaborative partnership with my subject, offering opportunities for Rubie to co-author their portrayal wherever possible. For example, I was unable to gain access to the radio station we see Rubie performing at so instead arranged for Rubie to film some of the performance on their phone (00:02:25), thereby giving them greater control over their depiction in this scene. I was, however, initially apprehensive about using the resulting footage. In some respects it felt mismatched with the rest of the film, as it was shot on an iPhone rather than the Sony A7S, and the sound quality was poor. The scene was also poorly framed: with the phone having been placed, we are denied a clear view of Rubie's performance as she continuously moves in and out of shot. Nevertheless, I decided that these imperfections provided an authentic representation of the chaotic, improvised conditions of production and helped to immerse the viewer in Rubie's world.

My desire to depict this authenticity extended throughout the post-production process, wherein I continued to incorporate what I considered to be moments where Rubie appeared unguarded, 
spontaneous or vulnerable. Such moments can be seen when Rubie awkwardly smiles to themselves (00:05:10), pushes their trolley through the streets (00:06:18) or simply yawns (00:09:28). I also wished to draw attention to facets of Rubie's character through experimental editing techniques, as shown in the sequence of close-up shots of flowers (00:01:33 - 00:01:59), mirroring the design on their album's cassette tape, as well as editing the visuals to move in time with Rubie's voice. In this, I hoped to bring the viewer into sync with Rubie's speech rhythms, demonstrating what Walter Murch asserts as "one of the central responsibilities of the editor": "to establish an interesting, coherent rhythm of emotion and thought - on the tiniest and the largest scales - that allows the audience to trust, to give themselves to the film." $\underline{23}$

In his book Speaking Truths With Film: Evidence, Ethics, Politics in Documentary, Bill Nichols states that "filmmakers bear considerable responsibility for the ethical decisions that inform their final film" and therefore must be aware of the inherent power they hold when portraying a subject. $\frac{24}{}$ Concurrently, this power relation is further complicated when considering the collaborative nature of (observational) documentary, as explored in Kate Nash's article "Telling Stories: The Narrative Study of Documentary Ethics." Here, Nash addresses the power and agency that a subject can hold in regards to the development of a documentary project, acknowledging that "participants ... can see themselves as active contributors to the documentary text." 25 As the production developed and the obstacles mounted, I found myself more and more reliant on Rubie's interest in maintaining this active contribution, as well as their personal investment and goodwill, in order to propel the project forward. Following the nationwide lockdown, I was no longer able to film and so I began conducting a series of recorded phone calls with Rubie. This period of the production was challenging, both on a personal and logistical level. However, the shared experience of the pandemic, coupled with the less intrusive methods of recording, allowed for a greater degree of intimacy to develop between us. As Nash asserts, "trust between documentary maker and participant develops gradually over time," and this trust would become an important factor in the subsequent stages of production. $\underline{26}$

As time progressed, it became clear that I would not have another opportunity to film with Rubie in person and therefore would need to rely on the telephone recordings instead. I began transcribing these conversations in order to build a paper edit. However, towards the end of this edit I discovered that my intended narrative arc, which focused on the logistics of streaming the album launch gig online, didn't fit with the footage I had. The storyline felt lacklustre and formulaic, while it also didn't allow me to explore the material that I found most interesting. I also wanted to convey some of the disruption and confusion that the Covid-19 pandemic had created. It did not feel possible to express this in a chronological narrative so I decided to abandon my original linear structure and return to the transcripts of my and Rubie's phone conversations. During this process I was unsure what exactly I was looking for, thereby unconsciously mirroring Murch's suggestion that, when editing, "you may not 
be able to articulate what you want, but you can recognize it when you see it."27 As I re-read the transcripts I began highlighting sections of Rubie's dialogue that resonated with me. At this point I was not able to outline what the film should be about, but I was able to discern which moments in our conversations felt most significant, thereby demonstrating what Murch describes as typical of the reediting process: "many times ... what you thought was originally unusable may come to be your salvation." $\underline{28}$

I ultimately decided to structure the film thematically rather than chronologically, allowing me to make connections between different aspects of Rubie's experience. I was particularly interested in the way that their trans identity had left them seeking a sense of belonging. This seemed to be echoed in the struggles they faced as an artist trying to express themselves in the isolation of the pandemic. In both instances, $\mathrm{F}^{*} \mathrm{Choir}$ provided an anchoring sense of community for Rubie and I therefore decided to centre the narrative on the theme of overcoming isolation to find community. I drew inspiration from Rubie's newest song, "Extra," which features the layered voices of $\mathrm{F}^{*} \mathrm{Choir}$ members singing into their phones. I hoped that this would provide an evocative climax to the film and asked Rubie if they would be willing to help me organise filming a virtual performance of the song.

This raised further ethical questions for me: was it unfair to ask Rubie and the choir members to give over their time for my project? How could I ensure that Rubie didn't feel pressured to fulfil my request? I decided to explain my difficulties to Rubie, outlining how the restrictions that the lockdown imposed meant I couldn't make the film I had originally envisioned and how I was struggling to make sense of the footage I had recorded. Despite my reservations, Rubie's response was very enthusiastic and they immediately set about organising the performance, thereby confirming for me that I had forged a healthy working relationship with Rubie, while also alleviating my concerns that the additional filming may be somewhat exploitative.

The inclusion of my own voice throughout the film further highlights the interactive and informal nature of our interviewer/interviewee relationship. It acts as a gentle reminder to the viewer that Rubie is a response to my social interactions with Rubie, as opposed to an impersonal exposition of Rubie. However, to ensure that I wasn't centring myself and pulling focus away from my subject, I chose to keep the inclusion of my voice to a minimum. Lastly, I also made sure to include Rubie in the process of writing this essay, and only allowed the film and accompanying writing to go public once they had provided their consent.

\section{Experimental Approaches and DIY Aesthetic}


In his article "With(in) Each Other: Sensorial Strategies In Recent Audiovisual Work," Laurent Van Lancker discusses how the filmmaker's choice of equipment can have an impact on their production of images, revealing his fondness for "small, handheld digital cameras" because of the "performative and corporeal dimension they allow." $\underline{29}$ Similarly, on my first shoot with Rubie I came to the realisation that I preferred the look and feel of handheld video footage, the static quality of tripod shots seeming at odds with the dynamic nature of Rubie's character. In contrast, the handheld camera allowed for a more playful, expressive and intimate engagement with Rubie. This is most evident in the footage of Rubie playing the piano, where I was able to move fluidly between close-ups of their hands and face (00:01:05). This visual presentation offers the viewer a more intimate experience of Rubie's expressive presence. As Van Lancker clarifies, "a heavy camera on the shoulder doesn't allow the same kind of exploration or searching for an image."

Acknowledging that the film I set out to make neither worked with the material I had recorded, nor did it feel like the story I wanted to tell, forced me to adopt a more experimental portrayal of Rubie and the effects that the global pandemic had on them. The resulting film substituted linear narrative conventions for a collage-like multimedia method of documentation. Drawing inspiration from Laurent Van Lanckers' films Surya (2006) and Disorient (2011), I used "asynchronous" approaches to sound and image to "induce a more synaesthetic sense production, [a] more corporeal experience ... and a more poetical knowledge." 31 By "creating images that the spectator cannot grasp immediately," Rubie invites the audience to "embark on an active journey" of sense making. $\underline{32}$ Furthermore, like Disorient, Rubie also uses a mixture of video formats in "a manner similar to a painter." $\underline{33}$ By blowing up the Zoom footage, I was able to magnify the texture and grain of the images which in turn serve to convey a "more sensorial, corporeal experience of the film than a solely illustrative reading of it allows." $\underline{34}$ As discussed above, this collage-like DIY aesthetic allowed for a plurality of representations whilst simultaneously echoing Rubie's own DIY approach to music making. This is highlighted in the scenes of Rubie soldering guitar cables (00:04:43), pushing equipment by trolley (00:00:36), and discussing the use of iPhone voice recordings in their song "Extra" (00:10:42).

The asynchronous moments of sound and image (see for example 00:00:00-00:00:17; 00:01:3300:02:00; 00:05:16-00:05:52) allow for a degree of ambiguity to permeate the narrative structure. By making the film less defined, I hoped to convey the sense of disorientation experienced as a result of the lockdown, whilst simultaneously addressing some of the ethical dilemmas that arise when portraying a marginalised subject such as Rubie. I wanted to allow for interpretations that were not limited by my conscious understanding of Rubie's experiences and approach the formation of meaning "as something ... emergent, rather than prefigured or planned." $\underline{35}$ This is crucial because it will never be possible for me as a straight cisgender male to fully understand Rubie's lived experience as a gender non-conforming person. Perhaps more importantly though, it is these moments that serve to 
reinforce Rubie's desire to construct a space where it is permissible "to be ... confused and not know" (00:01:10). It is from these personal spaces of 'unknowing' that Rubie's innovative, tender and captivating artistry pours out, transcending their individual experience of marginalisation to resonate with wider universal concerns. As Rubie states, the "uncomfortable, slippery, difficult things" are "something that all of us feel, a lot of the stuff that's big and unwieldy and complicated, and that's fine ... that's what the world is like" (00:01:06).

\section{Conclusion}

Through participatory and observational modalities of documentary filmmaking, and multimedia approaches to image and sound capture, I attempted to present an intimate and diverse portrayal of my subject Rubie. The exploration of universal themes such as identity, marginalisation, isolation and community, serve to contextualise Rubie's experience within a broader socio-political framework, and in doing so endeavours to heighten the viewer's empathy for them. However, despite my initial conception of the film's narrative, the Covid-19 pandemic radically changed what was possible for Rubie's performance and the parameters for filming. These restrictions inevitably meant that I was able to record much less footage than I would have liked and I was unable to pursue the original narrative that I had envisioned. In some respects, this caused the film to fall short of my initial expectations and it could therefore be regarded as a 'failure' under normative models of success. However, although the lockdown imposed limitations, it also generated new creative opportunities. The shared experience of isolation allowed for a greater degree of intimacy to arise between myself and Rubie, which in turn created space for a more compelling narrative to emerge. In exploring these themes through a queer lens, I began to question the foundational principles of the success/failure dichotomy and instead embraced different ways of appreciating the final film and the process of making it.

At various points throughout the making of the film, I found myself trying to guide conversations with Rubie towards certain outcomes, attempting to elicit particular reactions from them. I had imagined they might feel sadness or anger about the many disruptions to their album launch gig plans, and that the experience of lockdown would increase their sense of marginalisation. Yet, at each moment Rubie remained measured, reflective and humble about their experience. Rather than letting the disappointment of having to cancel their performance overwhelm them, they instead chose to find inventive alternatives to creative restrictions, and feel gratitude for the supportive people around them. This forced me to broaden and expand my understanding of the 'story' unfolding before me. I really had to interrogate whose story I was telling, as my own experience of lockdown became entangled with Rubie's, and my presuppositions clouded my judgement. This further highlighted my 
privileges as a white male within a heteronormative society, the complacency that can arise from holding this position, and the disorientation that occurs when this society is challenged. In contrast, Rubie's relative ambivalence could be perceived as representative of their attitude to a society that oppresses them: why would they be distressed about the upending of a society that treats them as an outsider?

On reflection, it feels strangely ominous that I am writing this on the first day of the new 2021 lockdown measures, nearly nine months on from the original announcement of lockdown in March 2020. Whilst I gained some sense of closure over the project, I am left with a greater sense of ambivalence about the months ahead. How much longer will this last? What will the fallout be? When will the world return to 'normal.' Yet, the process of making this film has shown me that an urgent need to return to 'normal' is misplaced. We should instead be using this opportunity to re-build a more communally inclusive new 'normal.'

\section{Bibliography}

Ahmed, Sara. Queer Phenomenology: Orientations, Objects, Others. Durham: Duke University Press, 2006.

Grimshaw, Anna, and Amanda Ravetz. "Rethinking Observational Cinema." Journal of the Royal Anthropological Institute 15, no. 3 (2009): 538-56.

Halberstam, Jack. The Queer Art of Failure. Durham: Duke University Press, 2011.

Halperin, David M. Saint Foucault: Towards a Gay Hagiography. New York: Oxford University Press, 1997.

Kornak, Jacek. “Queer as a Political Concept.” PhD diss., University of Helsinki, 2015.

Murch, Walter. In The Blink of an Eye: A Perspective on Film Editing. Los Angeles: Silman-James Press, 2001.

Nash, Kate. "Telling Stories: The Narrative Study of Documentary Ethics." New Review of Film and Television Studies 10, no. 3 (2012): 318-31.

Nichols, Bill. Introduction to Documentary. Bloomington: Indiana University Press, 2001. 
Nichols, Bill. Representing Reality: Issues and Concepts in Documentary. Bloomington: Indiana University Press, 2010.

Nichols, Bill. Speaking Truths With Film: Evidence, Ethics, Politics in Documentary. Oakland, California: University of California Press. 2016.

Schneider, Arnd, and Christopher Wright. Anthropology and Art Practice. London: Bloomsbury, 2013.

Välimäki, Susan. "The Audiovisual Construction of Transgender Identity in Transamerica." In The Oxford Handbook of New Audiovisual Aesthetics, edited by John Richardson, Claudia Gorbman, and Carol Vernallis, 372-388. Oxford: Oxford University Press, 2013.

Van Lancker, Laurent. "With(in) Each Other: Sensorial Practices In Recent Audiovisual Work." In Anthropology and Art Practice, edited by Arnd Schneider and Christopher Wright, 143-150. London: Bloomsbury, 2013.

\section{Media Cited}

CysMus - CESEM. "Day 2 - Part 2 (Afternoon)." YouTube video, 4:41:24. Streamed live on October 2, 2020. Accessed December 27, 2020. https://www.youtube.com/watch? $\mathrm{v}=$ laHhNCOHbeQ\&t=15102s\&ab channel=CysMus-CESEM.

Disorient. Directed by Laurent Van Lancker. Documentary. Brussels: Polymorfilms, 2011.

RuPaul's Drag Race. Directed by Nick Murray. TV Series. California: World of Wonder Productions, 2009-present.

Surya. Directed by Laurent Van Lancker. Documentary. Brussels: Polymorefilms, 2006.

Transamerica. Directed by Duncan Tucker. Film. New York: Belladonna Productions, 2005.

\section{Biography}


Josh Grey-Jung is an electronic musician, filmmaker and audio-visual artist. He is currently studying an MA in Creative Practice at Goldsmiths and a Foundation in Existential Psychotherapy at The New School of Psychotherapy and Counselling. His extended practice covers field recording, sound design, installation, sculpture, photography and music. His previous works have explored the themes of memory, trauma and liminality. He is currently writing and recording a solo album, and collaborating with director Taz Tron Delix on a new video installation project.

\section{Footnotes}

1. Jack Halberstam, The Queer Art of Failure (Durham: Duke University Press, 2011), 12.

2. See 00:01:18 in Rubie. $\subseteq$

3. Sara Ahmed, Queer Phenomenology: Orientations, Objects, Others. (Durham: Duke University Press, 2006), 157. $ヒ$

4. Ibid., 158. $\subseteq$

5. See 03:48:35 in CysMus - CESEM, “Day 2 • Part 2 (Afternoon)," October 2, 2020, December 27, 2020, https://www.youtube.com/watch? v=laHhNCOHbeQ\&t=15102s\&ab channel=CysMus-CESEM.

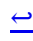

6. Ibid., 03:48:07; 03:48:18.

7. Halberstam, The Queer Art of Failure, 3. $\subseteq$

8. Jacek Kornak, "Queer as a Political Concept" (PhD diss., University of Helsinki, 2015), 205.

9. David M. Halperin, Saint Foucault: Towards a Gay Hagiography (New York: Oxford University Press, 1997), 62. $\leftrightarrows$

10. Halberstam, The Queer Art of Failure, $2 . \subseteq$

11. Ibid., $4 . \uplus$

12. Susan Välimäki, “The Audiovisual Construction of Transgender Identity in Transamerica," in The Oxford Handbook of New Audiovisual Aesthetics, ed. John Richardson, Claudia Gorbman, and Carol Vernallis (Oxford: Oxford University Press, 2013), 372 .

13. Ibid. $\doteq$

14. Halberstam, The Queer Art of Failure, $2 . \triangleq$ 
15. Ibid., $4 . \oplus$

16. Ibid., 2. $\doteq$

17. See 00:08:00 in Rubie.

18. Kate Nash, "Telling Stories: The Narrative Study of Documentary Ethics," New Review of Film and Television Studies10, no. 3 (2012): 322.

19. Bill Nichols, Representing Reality: Issues and Concepts in Documentary (Bloomington: Indiana University Press, 2010), 49.

20.

Anna Grimshaw and Amanda Ravetz, "Rethinking Observational Cinema," Journal of the Royal Anthropological Institute 15, no. 3 (2009): 550;

Bill Nichols, Introduction to Documentary (Bloomington: Indiana University Press, 2001), 123.

21. Grimshaw and Ravetz, "Rethinking Observational Cinema," 540.

22. Ibid., 545.

23. Walter Murch, In The Blink of an Eye: A Perspective on Film Editing, (Los Angeles: Silman-James Press, 2001), 72.

24. Bill Nichols, Speaking Truths With Film: Evidence, Ethics, Politics in Documentary (Oakland, California: University of California Press, 2016), 152.

25. Nash, "Telling Stories," $325 . \leftrightharpoons$

26. Ibid. $\subseteq$

27. Murch, In The Blink of an Eye, 47.

28. Ibid., $46 . \subseteq$

29. Laurent Van Lancker, "With(in) Each Other: Sensorial Practices In Recent Audiovisual Work," in Anthropology and Art Practice, ed. Arnd Schneider and Christopher Wright (London: Bloomsbury, 2013), 146.

30. Ibid.

31. Ibid., 145. 
32. Ibid., 147. $\subseteq$

33. Ibid., 146.

34. Ibid.

35. Arnd Schneider and Christopher Wright, "Ways of Working," in Anthropology and Art Practice, ed. Arnd Schneider and Christopher Wright (London: Bloomsbury, 2013), 1. 